\title{
Chapter 3 \\ What Synthetic Biology Aims At: Review Articles as Sites for Constructing and Narrating an Emerging Field
}

\author{
Clemens Blümel
}

\subsection{Introduction}

Analyses of scientific communities and collectives are central to Science and Technology Studies (STS) and sociological studies of science. In this article, I aim to elaborate on how the analysis of review articles can contribute to the analysis of synthetic biology as an epistemic community. Particularly in synthetic biology, community-building seems to benefit from growing societal awareness (Cserer and Seiringer 2009) as well as from new forms of organisational and scientific infrastructure. Community-building in this field, I suggest, can not only be explored by studying material spaces or events, such as conferences, workshops, or laboratories, but it may also be traced by exploring specific textual practices or representations within the scholarly discourse, in online commentaries, reports, or position papers.

Although much research on the topical landscape of societal and scholarly discourses in synthetic biology has been undertaken in recent years, these analyses have scarcely taken the specific contexts of publication-that is, the different scholarly or non-scholarly genres-into account. In this chapter, I will focus on the structure and content of review articles in synthetic biology. Characteristic framings of synthetic biology such as the notions of 'engineering biology' or 'synthesis and biology' (Kastenhofer 2013; Molyneux-Hodgson and Meyer 2009) have been articulated in this genre of scholarly literature (Benner and Sismour 2005; Endy 2005; Purnick and Weiss 2009). Other research on review articles (Myers 1991) has shown that they can contain presentations or characterisations of a research entity, which have an effect on the perception of a novel scientific

\footnotetext{
C. Blümel $(\square)$

Research area 'Research Systems and Science Dynamics', German Centre for Higher Education Research and Science Studies (DZHW), Berlin, Germany

e-mail: bluemel@dzhw.eu
} 
collective. Moreover, the mere existence and the relative share of review articles may be understood as an indicator of the state of a scientific field (Bastide et al. 1989). Thus, an analytical focus on review articles may be elucidating in the reconstruction of synthetic biology and of research collectives in general.

Based on a theoretical framework combining approaches from linguistics with sociological text analysis, I hence explore the relative structure and position of review articles in the publication landscape, the different types of review articles one finds in the field, how these review articles deal with research in the field, and how these reviews present the field as a whole. The chapter draws on bibliometric analysis and content analysis of scholarly documents. It is structured as follows: in the subsequent section, I will discuss different approaches to the analysis of review articles and develop a theoretical framework on how the existence or non-existence of this genre, its different types, and specific textual strategies can inform the study of scientific fields. After presenting my empirical approach in section three, I present major findings in section four. I conclude with a discussion of how findings of the study may contribute to the analysis of synthetic biology as a research field and to wider debates in STS.

\subsection{Review Articles, Genre Analysis and the Study of Scientific Fields}

The review article can be considered as a neglected genre in the analysis of scholarly discourse (Azar and Hashim 2014, p. 76; Bastide et al. 1989, p. 535). Contrary to the classic research article, which has often been framed as the "master narrative of our times' (Swales 2003), the scientific review article has not received similar attention among scholars in both the sociology of science and in linguistics. With a few exceptions (Bastide et al. 1989; Myers 1991), one finds almost no contributions of how the analysis of reviews can be used to study specific scientific fields. Most research on review articles has taken the perspective of genre analysis in science (Swales 1990), which focuses on the ways specific textual formats in science correspond to recurring situations by studying textual structure, argumentative patterns, and the usage of specific vocabulary in specific forms of academic discourse (Berkenkotter and Huckin 1993).

What is known from the literature so far is that there is no such thing as the scientific review (Azar and Hashim 2014; Virgo 1971; Woodward 1974). Rather, one finds different forms and types of review articles, which have been mainly established in the twentieth century. In 1961, John Adams (1961) distinguished between disciplinary review articles, which emerged from the annual report of the nineteenth century, and categorical review articles, which aim at selectively discussing specific solutions to specific problems. It is widely held that the latter depended much more on the personal styles of their authors (Azar and Hashim 2014, p. 76). Ten years later, Judy Virgo (1971, p. 279) complained about the rising 
number of these articles and the fact that one could hardly control this vastly increasing genre of scholarly writing. Linguistic research into the different practices of writing established that the typology of review articles in science can be further differentiated: Woodward (1974) has found that there are interpretive, critical, speculative, or even popular review articles. According to Azar and Hashim (2014), these findings show that review articles can appear in various forms, and their writing can comprise very different academic practices such as evaluating, problematising, or reporting (ibid., p. 77).

While scholars of linguistics have established different types and characteristics of review articles, little is known about the specific uses and functions of these types of text in the various disciplines and fields. Virgo (1971), for instance, argued that review articles in medicine are of a specific type and characteristic (meta reviews or systematic reviews) because they are read by a specific audience (ibid., p. 279). Few studies, however, have systematically taken the opposite approach to explore how reviews might inform the analysis of research collectives. One of these exemptions is the work of Bastide et al. (1989) who argue that the prevalence of reviews may be understood as an indicator of the state of a research field. They have proposed that the non-existence of reviews would indicate a 'low degree of maturity and organization', while the 'existence of reviews manifests a certain degree of development' (Bastide et al. 1989, p. 556). In addition, they also claimed to find specific types of reviews in novel fields and disciplines (ibid.).

If these findings are applied to what is known in science studies about the field of synthetic biology, one may expect a rather low number of reviews since the field is mostly understood as still emerging (Raimbault et al. 2016) and rather heterogeneous with various different epistemic orientations (Kastenhofer 2013). In order to establish a relationship between the type or content of reviews and the state of the field, I propose to more closely examine the specific ways of how review articles present, order, or deal with research in the field. Ordering activities are central to the textual practices of scientific review articles as they are supposed to report on trends within the epistemic trajectories of specific fields (Virgo 1971). As established above, reviews provide different forms of ordering when presenting, selecting, and highlighting research by establishing abstract categories, providing temporal relationships, or carving out fields of application.

One possible strategy to contribute to these discussions is to focus on selfcharacterisations of the field. According to Luhmann, self-characterisations are the means by which systems describe differences between themselves and their environment (Luhmann 1990). The concept of self-characterisation has recently been applied to explore the degree specific social entities reflect on themselves (Kaldewey 2013). It can be argued that the analysis of self-characterisations also contributes to the analysis of the states of scientific fields because different patterns of selfcharacterisation provide information about degrees of maturity and types of organisation in scientific collectives.

Increasingly, one finds research on self-characterisations which is related to identity work in science - that is, the ways how scientific fields establish and maintain views on themselves, their subject, or their mode of research. One of the 
means by which scientific collectives are constructed as valuable and meaningful entities is through categories or meta-categories of science (Shapin 2001), which often appear in secondary scholarly writing such as reviews (Myers 1991, 2003). These categories allow for characterising and comparing scientific fields by attributing to them specific qualities, which are then constructed as relevant and which most often signify wider use, such as interdisciplinarity, innovativeness, or novelty. The construction of categories as a means of valuation is particularly apparent in what Bastide et al. (1989) have called programmatic review articles which contain hierarchised lists of research questions. Along this line of reasoning, I will focus on how the field is presented to the reader in such a way that it appears as a credible, legitimate, relevant, or valuable entity and process. This can be attempted by relating specific forms of textual organisation to patterns of self-characterisation.

But there is another sort of persuasive textual repertoire-namely, narrative forms of ordering. It can be argued that such textual repertoires may be particularly apparent in historical or narrative review articles. Narrative forms of ordering in scholarly writing provide meaning and value by identifying and relating inaugural events, thereby constructing larger collectives. Lepenies and Weingart (1983) established that narrative presentations of science can contribute to a field's identity by providing a dominant frame or narration to which readers can attach. By focusing on different histories on molecular biology, Abir-Am (1985) found that the field had been constructed as 'rocket science' by presenting its history as a history of heroes. From these different bodies of research-genre studies (Bazerman 1988; Myers 1991, 2003) on the one hand as well as studies of disciplinary histories on the other (Abir-Am 1985) — it can be argued that reviews may contain different ways of ordering, presenting, and legitimating a scientific field, contributing to an understanding of the establishment and reproduction of scientific collectives. To empirically account for the role of review articles in the construction of scientific fields, one needs to more closely examine not only the position of reviews in relation to other types of text but also the modes of textual presentation in scientific fields.

Based on these considerations, I further specify the questions to be addressed in this chapter. First, what is the place of review articles within the publication landscape of synthetic biology in quantitative terms (e.g. what is the share of review articles in the field; what can be said about the citation figures of review articles within synthetic biology)? Second, what different forms and types of review articles do we find in synthetic biology publications? Third, what textual strategies are employed to present and value the field in these articles, and do these strategies change over time? And fourth, how do differences in presentation relate to the legitimation or valuation of the field? In the conclusion my empirical data will be used to derive implications for a better understanding of synthetic biology as a research field. 


\subsection{Methods}

The above-mentioned research questions require a careful integration of different perspectives and methods. More specifically, I combine content analysis of scholarly texts with quantitative analyses of publications.

In a first step, I analysed how review articles are represented in the field of synthetic biology in order to gain insights into the publication structure of the field and the role of review articles therein. To account for the field as a set of publications, I conducted a bibliometric analysis, paying particular attention to specific document types by relying on a topical search query strategy, using Web of Science (WoS) as a database. This search strategy was based on keywords combined with Boolean operators and additional components such as 'years'. I thereby followed the topical search approach of Tunger (2009), drawing on and further modifying the search strategy of Pei et al. (2012). ${ }^{1}$ Articles were collected for the years 2002-2012 in order to allow for the analysis of citation effects. I further refined the search by focusing on science and technology research domains. The full search algorithm reads as follows:

'Synthetic Biology' OR 'artificial cell' OR 'minimal genome' OR 'artificial system AND biology*' OR 'artificial ecosystem' OR 'XNA' OR 'Computational design NOT Engineering' AND 'Artificial Life'.

The query was iteratively complemented (date of the search: 10 December 2015). Finally, the resulting corpus was cleaned, resulting in 3406 synthetic biology articles. ${ }^{2}$ Relying on the information on documents types provided by Web of Science, this corpus allowed for comparisons between the different types of publications in the field, relating to the question of how frequent review papers are compared to other publication types in the field.

In a second step, I analysed a smaller set of review papers which had been generated from the initial corpus using citation counts as selection criterion in order to explore whether these had specific textual strategies of ordering knowledge and whether these strategies coincide with other textual structures, thus allowing for the identification of specific types of reviews. Relating to the work of Swales and Naijar (1987), I particularly concentrated on introductions and conclusions (Swales and Naijar 1987; Swales 1990). ${ }^{3}$ The material underwent a qualitative content analysis, utilising MAXQDA as a software package to support coding activities. The code system was developed from a mixture of inductive and deductive coding strategies (Kuckartz 2014). Theoretical categories were constructed by integrating concepts of genre analysis and studies of scientific texts, such as categories for order

\footnotetext{
${ }^{1}$ Further such studies include Oldham et al. (2012) and Raimbault et al. (2016). According to my re-analysis of the output generated by the search term of Pei et al. (2012), I found that the use of 'artificial system' as a key word can lead to systematic overestimation of search results and false positives.

${ }^{2}$ This figure was less than the outcome of the study conducted by Pei et al. (2012).

${ }^{3}$ Similar arguments for this selection have been engaged by Bastide et al. (1989).
} 
and structure of the text (Bastide et al. 1989) and for argumentation patterns (Bazerman 1988). The goal was to explore how different types of review articles are related to different ways of presenting and valuing the field of synthetic biology. Different analytical strategies were applied for identifying types of reviews in the field: a) textual markers of purposes in the text were analysed in order to account for explicitly mentioned textual goals, and b) specific modes of organising and ordering research in the field were explored which would lead more indirectly towards typifying review articles. Citation counts of the articles were considered in order to compare the different types of reviews regarding their visibility in the scholarly landscape. In a third step, different forms of textual organisation were related to specific field descriptions in order to account for how the field is constructed as a valuable entity. Referring to the concept of self-characterisation, I aimed at identifying and exploring particular passages which allowed for establishing specific relationships between textual organisation and ways of legitimating synthetic biology. Lastly, these different patterns were brought into a temporal order so as to account for the dynamics of synthetic biology in the period studied.

\subsection{Results}

\subsubsection{Reviews in the Field of Synthetic Biology}

The analysis of scientific literature revealed that the term 'synthetic biology' has been used as in titles, abstracts, or full texts in 3406 publications in 520 different journals.

Table 3.1 shows the percentage of different publication types in the abovementioned database. The most common document type is the classical research article with almost 1800 hits for this database and period (2002-2012). More than $16 \%$ of the articles in Synthetic Biology, however, are categorised as review articles in the WoS database, thus rendering this type of article the second most frequent document type in the corpus. ${ }^{4}$ Such a high share seems puzzling in a field that has

Table 3.1 Document types in synthetic biology

\begin{tabular}{l|l|l}
\hline Publication type & Absolute figures & Relative (in per cent) \\
\hline Review articles & 564 & 16.6 \\
\hline Research article & 1798 & 52.8 \\
\hline Data set & 308 & 9.0 \\
\hline Editorial material & 185 & 5.4 \\
\hline Other & 551 & 16.2 \\
\hline Total & 3406 & 100 \\
\hline
\end{tabular}

Source: Web of Science/Web of Knowledge (accessed May 2016)

\footnotetext{
${ }^{4}$ The share of review articles in synthetic biology is higher than in the total Web of Science (WoS) database output in the respective period (2002-2012), which is $1.9 \%$. Of course, the comparison
} 
Table 3.2 Top ten review articles of synthetic biology by times citation (TC)

\begin{tabular}{l|l|l|l|l}
\hline Year & Author & Title & Source & TC \\
\hline 2005 & Endy & Foundations for engineering biology & Nature & 558 \\
\hline 2009 & Li et al. & $\begin{array}{l}\text { Drug discovery and natural products: End of } \\
\text { an era or an endless frontier? }\end{array}$ & Science & 416 \\
\hline 2005 & Benner & Synthetic biology & $\begin{array}{l}\text { Nat Rev } \\
\text { Genet }\end{array}$ & 381 \\
\hline 2006 & $\begin{array}{l}\text { Andrianantoandro } \\
\text { et al. }\end{array}$ & $\begin{array}{l}\text { Synthetic biology: New engineering rules for } \\
\text { an emerging discipline }\end{array}$ & $\begin{array}{l}\text { Mol Syst } \\
\text { Biol }\end{array}$ & 296 \\
\hline 2009 & Purnick/Weiss & $\begin{array}{l}\text { The second wave of synthetic biology: From } \\
\text { modules to systems }\end{array}$ & $\begin{array}{l}\text { Nat Rev Mol } \\
\text { Cell Biol }\end{array}$ & 271 \\
\hline 2008 & Kell & Synthetic biology for synthetic chemistry & $\begin{array}{l}\text { ACS } \\
\text { Chem. Biol. }\end{array}$ & 219 \\
\hline 2010 & Khalil et al. & Synthetic biology: Applications come of age & $\begin{array}{l}\text { Nat Rev } \\
\text { Genet }\end{array}$ & 214 \\
\hline 2006 & Bhattacharya et al. & Domains, motifs, and scaffolds & $\begin{array}{l}\text { Annu. Rev. } \\
\text { Biochem }\end{array}$ & 212 \\
\hline 2008 & Veening et al. & $\begin{array}{l}\text { Bistability, epigenetics, and bet-hedging in } \\
\text { bacteria }\end{array}$ & $\begin{array}{l}\text { Annu. Rev. } \\
\text { Microbiol. }\end{array}$ & 199 \\
\hline 2005 & Sprinczak & Reconstruction of genetic circuits & Nature & 188 \\
\hline
\end{tabular}

Source: Web of Science (accessed 18 March 2016)

been repeatedly qualified as emerging when compared to the assumption put forward by Bastide et al. (1989)..$^{5}$

In order to gain more information about what these figures might mean-that is, what is actually established in these types of text-I conducted a content analysis of a set of review articles. As mentioned in the methods section of this article, review articles for content analysis were selected by citation count. Based on the WoS citation data, 80 of the most highly cited review articles from the original database $(\mathrm{N}=3406)$ were selected, of which 77 were subsequently analysed more closely. Table 3.2 shows the distribution of these selected publications over time, with a visible bias for earlier papers resulting from the selection criterion (i.e. more recent papers naturally accrue fewer citations in a shorter time span). The highest number of review articles within the sample dates from the year 2009 (Fig. 3.1).

Twenty-five of the most highly cited review articles were also among the 50 most highly cited articles in the total synthetic biology database, ${ }^{6}$ which is in line with previous findings that review articles have a higher probability of being cited than other document types (Knottnerus and Kottnerus 2009). The high percentage of

with the total output of WoS publications is problematic because the WoS database covers many fields and disciplines which differ greatly in terms of maturity and dynamic. But the share of review articles was also lower in fields of similar size and state of emergence, such as organic solar fuel cells, where the share of reviews comprised 3.2\% (WoS base) in the period under study.

${ }^{5}$ The assumption was that the frequency of review articles mirrors the maturity of a field; see Sect. 3.2.

${ }^{6}$ For full citation details, see the supplementary material of this article. 
Number of articles in the corpus per year

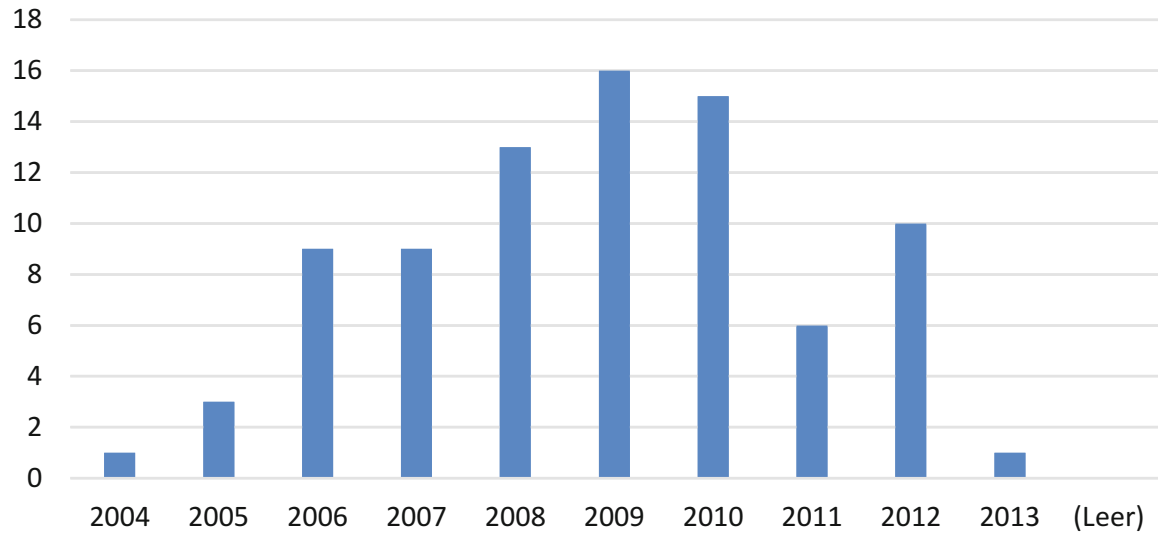

Fig. 3.1 Number of review articles in the sample corpus per year (2002-2012). (Source: Web of Science (accessed March 2016))

heavily cited review articles allows for framing the identified review as relevant for the analysis of the field, as they have been referred to extensively by the scholarly community.

In order to explore whether, and if so, how, these structural figures relate to the intellectual and social state of the field, I analysed the content and the textual strategies within the articles in more detail. If the existence and prevalence of specific types of review articles changes in the period studied, then one would assume corresponding changes in the maturity or organisation of the research field as proposed in the theoretical section of this chapter.

\subsubsection{Results of the Content Analysis}

\subsubsection{Types of Reviews in the Corpus}

Different types of reviews were identified by mapping codings from different categories-first, the (most often explicitly mentioned) purpose of the article, and second, the mode of textual presentation of research results (the latter with a set of relevant subcategories described in the next section). The analysis of purpose in documents is widely used in genre analysis because academic documents are primarily understood to be highly structured and purpose-oriented types of texts (Swales 1990). Hence, stated purposes were in most cases (64 out of 77) explicitly mentioned. Specific phrases directly related the purpose of the article to the document type, such as 'in this review we aim at providing an overview' (Purnick and Weiss 2009) or 'the purpose of this review is a discussion of another side of genomics' (Stähler et al. 2006) or 'in this review, we describe recent 
accomplishments'. In order to account for the diversity of the purposes provided within the set of articles, I analysed the verbs which were used to specify the focus of an article. Rather neutral phrases ('describe', 'providing [an] overview', and to a lesser extent, 'discuss') were common, coinciding with what Virgo (1971) has established as the functions of reviews - that is, to select and to provide oversight. In some cases, however, I also found explicit claims to establish goals and future directions of the research field, particularly in the early years (2005-2008):

In this review, we describe what has been done thus far in synthetic biology and how the field is actively being moved forward, as well as survey various prospective views that articulate different visions of synthetic biology's future. (Drubin et al. 2007)

Another source for the identification of different types of reviews was their modes of textual organisation. These modes were coded inductively following two main strategies: firstly, I analysed how the texts established author-reader relationships, using specific repertoires of connecting the different parts of the text-that is, specific repertoires which aim at broadening the readership by referring to merely public knowledge concepts and science policy semantics. And second, I explored the ways in which the reviews dealt with the different contributions to the research field. I found that these different strategies often lead to codings of similar textual passages.

Thus four different modes emerged: evaluation-passages that aimed at highlighting and valuing specific contributions in the research field; classification-passages that related research to existing or novel epistemic categories; exemplification-passages that exemplify specific research to make a broader claim about the field; and narration — passages providing a meaningful sequence of events. I then continued to produce case specific summaries of codings in order to decide whether a specific mode of textual organisation dominates a text as a whole (Kuckartz 2014, p. 70). Based on these findings, I explored the relation between the different codes and categories - that is, modes of textual organisation, structure, and purpose of the text. I came up with three different types of reviews.

One set of review articles was dominated by exemplification. Endy (2005), for instance, does not provide a full discussion of research contributions but rather proposes a new frame of what engineering in biology means by providing examples of research projects which illuminate his vision of biology. Exemplifying articles often provided a principle or an abstract criterion (Andrianantoandro et al. 2006; Khalil and Collins 2010) or even a set of overarching principles (Benner and Sismour 2005; Endy 2005; Pleiss 2006) in order to organise research. This type of review can be found particularly in the years between 2005 and 2008. The respective articles share further features, such as a specific use of expectations ${ }^{7}$ in their introductions, relating the above-mentioned abstract criteria with a vision of how

\footnotetext{
${ }^{7}$ It has already been established elsewhere (Kastenhofer 2013; Blümel 2016) that synthetic biology is strongly characterised by using expectations. In this article, I established in particular that reviews are important sites for articulating visions, which may have affected their visibility in the publication landscape.
} 
the field may influence or impact on other fields or societal realms as in the following example:

Synthetic biology will revolutionize how we conceptualize and approach the engineering of biological systems. The vision and application of this emerging field will influence many other scientific and engineering disciplines, as well as affect various aspects of daily life and society. (Andrianantoandro et al. 2006)

I labelled this type 'prospective review'. This type included the most highly cited articles in the corpus (Endy 2005; Benner and Sismour 2005; Andrianantoandro et al. 2006; Isaacs et al. 2006) ${ }^{8}$ potentially indicative of raising the most awareness among (different) scientific communities. They can claim novelty for describing a recently emerging entity, e.g., a new collective. ${ }^{9}$ Given that many of the prospective review articles in this corpus cite each other, the prevalence of these articles may also indicate a kind of collective willingness to establish 'futures' of synthetic biology. What is more, the majority of review articles in the corpus can be referred to this type ( $\mathrm{N}=35)$. Different to what Bastide et al. (1989) have established, the prevalence of such reviews would then indicate the emergence of scientific fields instead of maturity of a scientific field.

By contrast, another set of review articles was dominated by narrative sequences. Following Arnold (2012), a narrative structure is understood as an interrelated pattern of events that allows for identifying a subject (synthetic biology) and a specific object (e.g. the construction of novel biosystems) in such a way that the various moments which hindered or enabled the solution of problems (lack or existence of resources, technologies, collaborations) are meaningfully presented. In such reviews (Khalil and Collins 2010; Purnick and Weiss 2009), several events were closely related as being part of similar technological advances, predecessors, or consequences of innovations in the field. Thus, by classifying specific review articles in the sample corpus as narrative, I found that major contributions in the research field were presented not only in a temporal order but also embedded in a larger (hi)story. In various review articles (Drubin et al. 2007; Mukherji and van Oudenaarden 2009), distinct epistemic events, such as the construction of genetic devices (Elowitz and Leibler 2000), were connected to construct a specific presentation of synthetic biology. Some of these articles even provided their own history of the field (Cheng and Lu 2012; Khalil and Collins 2010; Luisi et al. 2006; Mukherji and van Oudenaarden 2009; Stephanopoulos 2012). These review articles appear to be more frequent in the period from 2007 onwards. And, on average, they receive

\footnotetext{
${ }^{8}$ The above-mentioned article by Andrianantoandro et al. 2006 has been cited almost 300 times (according to the WoS database). Similar citation counts can be found for an article by Purnick and Weiss, which has been cited 271 times (data obtained from WoS).

${ }^{9}$ More research into the reception of scientific literature would be needed in order to establish a relationship between the use of visionary language and citation patterns.
} 
fewer citations than prospective review articles ${ }^{10}$ which might indicate that these articles attract less attention among scientific communities.

A third set of review articles was dominated by evaluative textual passages. (see also Sect. 3.2 of this article). Often, these articles highlighted benefits of synthetic biology for specific applications or application areas, such as biofuels, materials, clinical applications, or chemical compounds. As the citation figures show (Table 3.2), only one article of this type (Veening et al. 2008) features among the ten most highly cited articles in this sample. It is more difficult to attribute these review articles to a specific period, but they became more frequent in the years after 2010.

Based on these different purposes and ways of organising and structuring the text, I identified three different types of review articles in the sample corpus: prospective or programmatic reviews, categorical reviews, and narrative or historical reviews. The distribution of citation patterns suggests that particularly prospective and to a lesser extent narrative review articles became objects of intense discussion in the scholarly community. The high number of prospective reviews in the early period suggests that a specific type of review articles may play an important role in the emergence of the field.

\subsubsection{2 'What Synthetic Biology Aims At': Strategies of Self-Characterisation}

After having established these different types of review articles and their characteristics, I now come to the third question of how these texts differ in presenting the field.

Relying on the theoretical positions established in Sect. 3.2, I argue that in order to study the state of a research field by applying rhetoric and argumentative studies, one may need to focus on reconstructing the different ways the field is presented. On a conceptual level, these passages can be understood as self-characterisations of the field. Based on the findings of Pnina Abir-Am (1985), it can be argued that presentations of a field are seldom neutral but allow for valuing research in a respective area. To explore presentations of the field, I relied on a specific but frequent $(\mathrm{N}=64)$ type of textual passage, which I have termed 'field description', which highlights the boundaries and objects of research. These passages often contained a definition of the field and highlighted a specific goal towards which 'synthetic biology would head' or 'aim at' (Drubin et al. 2007; Pleiss 2006). These field descriptions were highly connected with other codes (referring to modes of textual organization) in that they contain a high number of rhetoric strategies, like metaphors, analogies, or comparisons. Following the theoretical considerations presented in Sect. 3.2, these passages were suitable candidates for exploring what has been termed the field's

\footnotetext{
${ }^{10}$ The effect that review articles published earlier are more likely to receive higher citations has been taken into account in this analysis.
} 
self-characterisation. The function of the field descriptions in the organisation of the review is particularly apparent in the following example:

The evolving discipline of synthetic biology overlaps with efforts in Metabolic Engineering and provides a complementary framework for the de novo design of new biosynthetic pathways. Synthetic Biology aims to frame the engineering of biology in a manner that is analogous to other engineering disciplines and relies on core principles of design and characterization to facilitate and the rapid and reproducible deployment of biological machines. (Prather and Martin 2008)

In this example, the field of synthetic biology was related to and demarcated from other fields (such as metabolic engineering). The presentation of the field came with a set of analogies, core principles, and possible application fields which allowed for qualifying and valuing research in this area.

A closer examination of other field descriptions from different periods reveals that field descriptions differed in how they are textually arranged and how they present synthetic biology as a collective entity. The set of prospective reviews (covering mainly the period from 2005 to 2008) started with stating the potential of synthetic biology (Andrianantoandro et al. 2006; Heinemann and Panke 2006), which was often connected to the articulation of a goal which the field should accomplish in the future (Benner 2003; McDaniel and Weiss 2005). Furthermore, the field was characterised by applying meta-categories such as 'highly interdisciplinary' (Endy 2005), 'emerging' (Isaacs et al. 2006), 'novel' (Sprinzak and Elowitz 2005), 'innovative', or 'application oriented' (Kaznessis 2007).

Yet, in the narrative or historical type of reviews, which were mainly published after 2008, field descriptions had a slightly different structure in that they highlight epistemic categories as attributes of the field, such as xeno-biology (Schmidt 2010) or advanced genetic circuitry (as in, for instance, Nandagopal and Elowitz (2011)). There were also changes in the tense describing the field from future tense ( $\mathrm{N}=13$ ) — 'what the field ought to be' to present tense-'what synthetic biology is' (see, for instance, as an example). Moreover, the review articles in the period from 2008 onwards often provided their own history of synthetic biology (Khalil and Collins 2010; Mukherji and van Oudenaarden 2009), supported by a greater use of pictures and graphical material (such as timelines). This shows that different types of reviews also accompany differences in presenting the field, reflecting the differences which have been established for these texts as a whole.

\subsubsection{From Authoritative to Narrative Forms of Community- Building: Changes in Legitimating the Field}

Finally, I address the questions of how these different ways of presenting research result in different practices of legitimating the field, and what this could mean for the use of reviews in the analysis of scientific fields and communities. It has been established in the theoretical section of this article that the articulation and construction of self-characterisation can play an important role in establishing collective identities of scientific fields. The ways by which novel or emerging scientific 
collectives are characterised can have performative effects on the perception of the community. I argue that accounts of self-characterisation also relate with attempts of legitimating the field as a credible or relevant community. Yet, the frequency of selfcharacterisations and the repertoires which are used to legitimate a field in these contexts may vary and may indicate different levels of maturity. Therefore, I have elaborated on the different repertoires of legitimation in these contexts.

Prospective and narrative review articles differed in that regard. Prospective reviews mainly employ authoritative legitimating strategies deriving the field's credibility from endeavours established earlier or by referring to success stories of other areas. One of the ways by which legitimacy is sought can be termed niche building - that is, situating the field of synthetic biology in the larger context of scientific discoveries (McDaniel and Weiss 2005, p. 4769).

Rhetorically, the field of synthetic biology was also presented as one solution to a problem that had been established earlier (e.g. Andrianantoandro et al. 2006, p. 1). Thus, the field was placed within a larger history of scientific progress. In this example, synthetic biology was presented as a consequence of various sequences of innovations which ultimately led to the emergence of the field. The mode of locating synthetic biology within various credible endeavours also attributed significance to its current state. Synthetic biology was hence presented as an extension of genetic engineering on the systems level. It was these (external) movements and discoveries from which the legitimacy and credibility of synthetic biology (as an extension thereof) is derived.

Another rhetorical means by which the field was legitimated is the use of comparisons and analogies to other scientific fields and disciplines. The use of historical comparisons for legitimating and establishing scientific collectives can also be found in other fields (Abir-Am 1985; Lepenies and Weingart 1983) and has already been studied for synthetic biology (Bensaude Vincent 2013). Generally, the use of comparisons with established fields has various effects: it establishes the author-reader relationship by referring to taken-for-granted knowledge, at least among large parts of the readership (Berger and Luckmann 1969/2013). Moreover, providing examples in scientific writing is often used to broaden the readership of articles beyond the narrowly defined research community.

It can be argued that the textual use of comparisons is to ensure that a broad readership can follow the argument if comparisons and analogies refer to taken-forgranted repertoires of social knowledge which are widely shared in the social world (Berger and Luckmann 1969/2013). Another use of comparisons may also be as a means of presenting a given but perhaps contested issue as more realistic or less problematic (Lepenies and Weingart 1983). ${ }^{11}$ In these cases, the comparison functions as a transfer of credibility which allows for framing the novel issue as a plausible way of doing or knowing things. Connecting established fields to (potentially) promising implementations in synthetic biology is not a single phenomenon

\footnotetext{
${ }^{11}$ For a general argument about comparisons in the context of synthetic biology, see also Torgersen and Schmidt (2013).
} 
but a recurring issue in the 2005-2008 reviews (Heinemann and Panke 2006). The comparison to an established practice then appears to be less relevant for characterising the field than for emphasising what synthetic biologists will soon be capable of. This mode of relating an established scientific practice to a potentially relevant but yet not existing implementation of synthetic biology concepts was frequently found in the sample.

In the second period after 2008, the rhetorical means by which the field was legitimated (except those that have been classified as categorical) can be termed narrative normalisation. What differed to the strategies of valuation and legitimation was that they did not rely-or did so to a lesser extent-on external resources, such as analogies or comparisons to other fields. Instead, these articles and the selfcharacterisations of synthetic biology often contained their own history of the field with more specific problems and challenges. They thereby established a specific agency and frame of the field by providing initial and foundational events. Purnick and Weiss (2009), for instance, presented a foundational disciplinary history in which simple genetic circuitries (oscillators and switches) had a specific role. The authors stated that their mode of textual presentation predominantly exemplified specific phases of the field:

We begin this review by examining the first wave in synthetic biology, a phase that has focused on creating and perfecting genetic devices and small modules. We do not provide a comprehensive discussion of synthetic biology projects, but rather a description of several informative examples. (Purnick and Weiss 2009)

Different to other prospective reviews in the sample, research contributions were not presented to demonstrate the state of the community; rather, each of the presented examples had a specific role in narrating the field. This fits well with what Arnold (2012, p. 21) has called the narrative structure of texts, which is the way a subject (e.g. synthetic biology) is established to master a specific goal. Purnick and Weiss listed problems the field had already mastered and specified new ones which needed to be addressed if the field were to reach its overarching goals (Purnick and Weiss 2009, p. 411). Hence, Purnick and Weiss combined a foundational history of the field with an articulation of future challenges and current necessities.

Khalil and Collins (2010) performed a similar form of valuation and legitimation by providing another narration of the field. In their introductory section (ibid., p. 367), the description of the field was related to a history about the first genetic devices of synthetic biology. Such framing by first discoveries played a less dominant role than in the field characterisations of the earlier prospective review articles (McDaniel and Weiss 2005; Benner 2003; Sismour and Benner 2005; Andrianantoandro et al. 2006; Heinemann and Panke 2006; Pleiss 2006). Khalil and Collins additionally framed the field by referring to founding events. In this narrative of self-characterisation, these events appeared as a coherent story in which a specific narrative of engineering appeared as a common denominator of all descriptive elements. Different to earlier review articles (Pleiss 2006, p. 736; Heinemann and Panke 2006; Benner and Sismour 2005) which had accounted for different disciplinary orientations and 'flavors' of synthetic biology, the overarching 
narrative of engineering was not contested any more. Such narrative streamlining of the field's development became most apparent in the latest article of the database, which described forward engineering as the only goal and identity of synthetic biology. Cameron et al. (2014) did so by providing 'milestones' of the field which fit this framing (ibid., p. 382) and devising phases of the field accordingly. Specific importance was attributed to the 'foundational' years (ibid.) 2000-2003. In this way, a dedicated narrative of synthetic biology as an engineering field in the making was deployed, establishing and stabilising the field as a quasi-discipline by providing it with its own history. This parallels Abir-Am's (1985) analysis of the way several scholars and spokesmen contributed to the consolidation of molecular biology by providing it with a specific history (ibid., p. 75). Other than this study, the narrative review articles discussed in this chapter make less use of foundational fathers, heroes, or spokesmen (e.g. Delbrück or Lura) but rather draw on 'inaugural devices' (Khalil and Collins 2010), such as repressilators, oscillators, and other technical tools that first exemplified ideas of what has later been termed synthetic biology (Blümel 2016).

Thus, differences in presenting synthetic biology were linked to different strategies and uses of legitimation and valuation. While the earlier prospective review articles relied on authoritative strategies of legitimating the field by focusing on broader trajectories of scientific discovery or on analogies to other fields, the more recent narrative reviews relied on quasi-disciplinary histories, depicting a story-line fraught with challenges, actors, and events. For the analysis of synthetic biology as a research field, this suggests that the field has undergone changes in the way it is perceived, presented, and discussed by its proponents. Thus, the field has undergone processes of institutionalisation and stabilisation. The finally dominant narrative focus on 'heroic objects' can be perceived as a story which contributed to the establishment of field specific sources of self-perception, legitimation, and credibility.

\subsection{Conclusion}

In this article, I explored how a discourse analysis focusing on review articles can contribute to the understanding of synthetic biology as an evolving research field. Based on explorations of previous research on this genre, I proposed that the analysis of review articles is a suitable way to explore self-characterisations of synthetic biology, allowing for reconstructing ways of attributing the field's credibility, legitimacy, and value. I articulated four different research questions and subsequently addressed them in reference to my empirical findings.

In order to account for the first question pertaining to the role of review articles in the publication landscape of synthetic biology, I conducted a bibliometric analysis, referring to the distribution of different publication types in the field. The share of review articles proved to be relatively high compared to average figures in the WoS database and to other comparable fields. Different to what (Bastide et al. 1989) 
proposed, review articles were highly prevalent in all stages of the emerging field, albeit with changes to their argumentative scheme (see below).

In order to elaborate in more detail the ways of ordering, presenting, and legitimating synthetic biology in review articles, I applied a qualitative content analysis which was informed by the aforementioned bibliometric analysis. Addressing the second research question, I established different types of reviews along different articulated purposes as well as differences in ways of ordering and textual organisation: a prospective type, which provided visions and prospects of the field; a categorical type, focusing on specific applications; and, third, a narrative type of review articles. Since the prevalence of these different types in the selected sample of the 77 most-cited review articles corresponds to specific phases of the field, it can be argued that the character of review articles has changed within the period at hand (2002-2012).

In order to account for the third question, I analysed the textual strategies employed to present the field as a whole. I found that textual strategies of presenting the field differed in accordance with the aforementioned types of reviews. Prospective reviews dealt with the depicted contributions to the field by means of exemplifying or illuminating abstract criteria, while narrative reviews ordered the reported contributions to the field along founding events which mirrored the progress of the field. I argued that these different strategies coincide with different ways of valuing or legitimating the field. Whereas the early 'prospective' review articles often provide comparisons and analogies to established disciplines in order to legitimate and justify the field, narrative review articles strongly relied on founding tales of the field, establishing and stabilising specific contributions as milestones within a specific history of the field.

Based on these findings concerning the ways of ordering, presenting, and legitimating the field in review articles, implications for the study of synthetic biology and other emerging scientific fields can be established. First, from analysing the content of the review articles, it can be concluded that the self-characterisation of the field is a recurring issue in synthetic biology; many textual passages address what the field aims at and what it stands for, indicative of a contested or tentative identity. The different structures and strategies of the three dominant types of review articles, however, point towards the prevalence of different developmental stages of the field. Early 'prospective' review articles aim at establishing synthetic biology as a valuable and legitimate field by referring to external resources. By contrast, the later narrative review articles from the years 2009 onwards indicate that the field may have already experienced and successfully managed conflicts over its intellectual orientation. Existing literature on synthetic biology has already shown that proponents of the field make use of futuristic visions (Kastenhofer 2013) in order to legitimise the field or to raise awareness among different audiences (Cserer and Seiringer 2009; Pei, Gaisser, and Schmidt 2012). Findings from this article contribute to this literature but show that different strategies of acquiring legitimacy have been used in the emergence of the field at different stages.

These findings also have implications for research on specific rhetorical devices and their role in establishing the identity of synthetic biology. Recently, Nerlich and 
McLeod (2016) pointed out that the field has made great use of such devices to promote itself. Other research highlighted how presentations of synthetic biology benefit from the use of comparisons and analogies to other fields (Bensaude-Vincent 2013). The findings presented in this chapter contribute to this line of research by arguing for a stronger consideration of different types and contexts of publications.

Thirdly, the findings presented here also relate to a larger body of research on narratives and narrations in science. Recently, Mary Morgan (2017) established that narratives and narrations are a widespread and pervasive practice across different scholarly domains. Narrative ordering thus is a way to 'answer how and why things happen' and plays an important role in many scientific contexts. Narrative forms of ordering also play a particular role in legitimating and valuing novel scientific fields. For instance, Abir-Am (1985) and Lepenies and Weingart (1983) provided insights into how the narrative presentation of scientific fields contributed to their establishment. Yet, while Abir-Am (1985) elaborated on how the narrative construction of founding heroes contributed to creating collective identities in molecular biology, the founding tales of synthetic biology culminate in presenting inaugural devices as 'heroic objects'. I argue that the construction of these founding stories can be understood as a form of narrative community-building, contributing to the fields' collective understanding of identity and configurations of agency. Thus, analyses of collective narrations in review articles can provide a different perspective on the reconstruction of emerging scientific fields such as synthetic biology.

\section{References}

Abir-Am, P. 1985. Themes, genres and orders of legitimation in the consolidation of new scientific disciplines: Deconstructing the historiography of molecular biology. History of Science 23 (1): 73-117.

Adams, S. 1961. The review literature of medicine. Bibliography of Medical Reviews: 6.

Andrianantoandro, E., S. Basu, D.K. Karig, and R. Weiss. 2006. Synthetic biology: New engineering rules for an emerging discipline. Molecular Systems Biology 16: 1-14.

Arnold, M. 2012. Erzählen. Die ethisch-politische Funktion narrativer Diskurse. In Erzählungen im Öffentlichen: Über die Wirkung narrativer Diskurse, ed. M. Arnold, G. Dressel, and W. Viehöver, 17-64. Springer.

Azar, A.S., and A. Hashim. 2014. Towards an analysis of review article in applied linguistics: Its classes, purposes and characteristics. English Language Teaching 7 (10).

Bastide, F., J.P. Courtial, and M. Callon. 1989. The use of review articles in the analysis of a research area. Scientometrics 15: 535-562.

Bazerman, C. 1988. Shaping written knowledge: The genre and activity of the experimental article in science. Madison/Wisconsin/London: The University of Wisconsin Press.

Benner, S.A. 2003. Synthetic biology: Act natural. Nature 421: 118.

Benner, S.A., and A.M. Sismour. 2005. Synthetic biology. Nature Reviews Genetics 6: 533-543.

Bensaude Vincent, B. 2013. Discipline-building in synthetic biology. Studies in History and Philosophy of Science Part C: Studies in History and Philosophy of Biological and Biomedical Sciences 44 (2): 122-129.

Berger, P., and T. Luckmann. 2013. Die gesellschaftliche Konstruktion der Wirklichkeit. Frankfurt am Main: Fischer. (Original work published 1969.). 
Berkenkotter, C., and T.N. Huckin. 1993. Rethinking genre from a sociocognitive perspective. Written Communication 10 (4): 475-509.

Blümel, C. 2016. Enrolling the toggle switch: Visionary claims and the capability of modeling objects in the disciplinary formation of synthetic biology. NanoEthics 10 (3): 269-287.

Cameron, E.D., C.J. Bashor, and J.J. Collins. 2014. A brief history of synthetic biology. Nature Reviews Microbiology: 381-390.

Cheng, A.A., and T.K. Lu. 2012. Synthetic biology: An emerging engineering discipline. Annual Review of Biomedical Engineering 14: 155-178.

Cserer, A., and A. Seiringer. 2009. Pictures of synthetic biology: A reflective discussion of the representation of synthetic biology in the German media and by SB experts. Systems and Synthetic Biology 3 (1-4): 27-35.

Drubin, D.A., J.C. Way, and P.A. Silver. 2007. Designing biological systems. Genes \& Development 21: 242-254.

Elowitz, M., and S.A. Leibler. 2000. A synthetic oscillatory network of transcriptional regulators. Nature 403: 335-338.

Endy, D. 2005. Foundations for engineering biology. Nature 438: 449-453.

Heinemann, M., and S. Panke. 2006. Synthetic biology—Putting engineering into biology. Bioinformatics 22 (22): 2790-2799.

Isaacs, F.J., D.J. Dwyer, and J.J. Collins. 2006. RNA synthetic biology. Nature Biotechnology 24 (5): 545-554.

Kaldewey, D. 2013. Wahrheit und Nützlichkeit. Bielefeld: transcript.

Kastenhofer, K. 2013. Synthetic biology as understanding, control, construction, and creation? Techno-epistemic and socio-political implications of different stances in talking and doing technoscience. Futures 48: 13-22.

Kaznessis, Y.N. 2007. Models for synthetic biology. BMC Systems Biology 1: 47.

Khalil, A.S., and J.J. Collins. 2010. Synthetic biology: Applications come of age. Nature Reviews. Genetics 11 (5): 367-379.

Knottnerus, J.A., and B.J. Kottnerus. 2009. Let's make the studies within systematic reviews count. The Lancet 373 (9675): 1605.

Kuckartz, U. 2014. Qualitative Inhaltsanalyse, Methoden, Praxis, Computerunterstützung, 2. Auflage. Weinheim/Basel: Juventa.

Lepenies, W., and P. Weingart. 1983. Introduction. In The functions and uses of disciplinary histories, ed. L. Graham, W. Lepenies, and P. Weingart, IX-XX. Dordrecht: D. Reidel Publishing Company.

Luhmann, N. 1990. Die Wissenschaft der Gesellschaft. Frankfurt am Main: Suhrkamp.

Luisi, P.L., C. Chiarabelli, and P. Stano. 2006. From never born proteins to minimal living cells: Two projects in synthetic biology. Origins of Life and Evolution of Biospheres 36: 605-616.

McDaniel, R., and R. Weiss. 2005. Advances in synthetic biology: On the path from prototypes to applications. Current Opinion in Biotechnology 17: 476-483.

Molyneux-Hodgson, S., and M. Meyer. 2009. Tales of emergence-Synthetic biology as a scientific community in the making. BioSocieties 4 (2-3): 129-145.

Morgan, M.S. 2017. Narrative ordering and explanation. Studies in History and Philosophy of Science 62: 86-97.

Mukherji, S., and A. van Oudenaarden. 2009. Synthetic biology: Understanding biological design from synthetic circuits. Nature Reviews Genetics 10: 859-871.

Myers, G. 1991. Stories and styles in two molecular biology review articles. In Textual dynamics and the professions: Historical and contemporary studies of writing in Professional communities, ed. C. Bazerman and Paradis, 45. Madison: The University of Wisconsin Press.

2003. Discourse studies of scientific popularization: Questioning the boundaries. Discourse Studies 5 (2): 265-279.

Nandagopal, N., and M.B. Elowitz. 2011. Synthetic biology: Integrated gene circuits. Science (New York, N.Y.) 333 (6047): 1244-1248. 
Nerlich, B., and C. McLeod. 2016. The dilemma of raising awareness 'responsibly': The need to discuss controversial research with the public raises a conundrum for scientists: When is the right time to start public debates? EMBO Reports 17 (4): 481-485.

Oldham, P., S. Hall, G. Burton, and J.A. Gilbert. 2012. Synthetic biology: Mapping the scientific landscape. PLoS One 7 (4): e34368.

Pei, L., S. Gaisser, and M. Schmidt. 2012. Synthetic biology in the view of European public funding organisations. Public Understanding of Science 21 (2): 149-162.

Pleiss, J. 2006. The promise of synthetic biology. Applied Microbiology and Biotechnology 73: 735-739.

Prather, K.L.J., and C.H. Martin. 2008. De novo biosynthetic pathways: Rational design of microbial chemical factories. Current Opinion in Biotechnology 19 (5): 468-474.

Purnick, P., and R. Weiss. 2009. The second wave of synthetic biology: From modules to systems. Nature Reviews Molecular Cell Biology 10: 410-422.

Raimbault, B., J.-P. Cointet, and P.-B. Joly. 2016. Mapping the emergence of synthetic biology. PLoS One 11 (9): e161522.

Schmidt, M. 2010. Xenobiology: A new form of life as the ultimate biosafety tool. BioEssays 32: 322-331.

Shapin, S. 2001. How to be antiscientific? In The one culture? A conversation about science, ed. J.K. Labinger and H.M. Collins, 99-115. Chicago: University of Chicago Press.

Sismour, M., and S. Benner. 2005. Synthetic biology. Nature Reviews Genetics 6: 533-543.

Sprinzak, D., and M. Elowitz. 2005. Reconstruction of genetic circuits. Nature 438.

Stähler, P., M. Beier, X. Gao, and J.D. Hoheisel. 2006. Another side of genomics: Synthetic biology as a means for the exploitation of whole-genome sequence information. Journal of Biotechnology 124: 206-212.

Stephanopoulos, G. 2012. Synthetic biology and metabolic engineering. ACS Synthetic Biology 1 (11): 514-525.

Swales, J. 1990. Genre analysis: English in academic and research settings. Cambridge: Cambridge University Press.

- 2003. 'That master narrative of our time': The research article revisited. The 14th European symposium on language for special purposes: Communication, culture, knowledge, University of Surrey, Guildford, UK.

Swales, J., and H. Naijar. 1987. The writing of research article introductions. Written Communication 4 (2): 175-191.

Torgersen, H., and M. Schmidt. 2013. Frames and comparators: How might a debate on synthetic biology evolve? Futures 48: 44-54.

Tunger, D. 2009. Bibliometrische Verfahren und Methoden als Beitrag zu Trendbeobachtung underkennung in den Naturwissenschaften. Schriften des Forschungszentrums Jülich Band 19: Jülich.

Veening, J.-W., W.K. Smits, and O.P. Kuipers. 2008. Bistability, epigenetics, and bet-hedging in bacteria. Annual Review of Microbiology 62: 193-210.

Virgo, J. 1971. The review article: Its characteristics and problems. The Library Quarterly 41 (4): 275-291.

Woodward, A. 1974. Review literature: Characteristics, sources and output in 1972. ASLIB Proceedings 26 : $367-376$. 
Open Access This chapter is licensed under the terms of the Creative Commons Attribution 4.0 International License (http://creativecommons.org/licenses/by/4.0/), which permits use, sharing, adaptation, distribution and reproduction in any medium or format, as long as you give appropriate credit to the original author(s) and the source, provide a link to the Creative Commons license and indicate if changes were made.

The images or other third party material in this chapter are included in the chapter's Creative Commons license, unless indicated otherwise in a credit line to the material. If material is not included in the chapter's Creative Commons license and your intended use is not permitted by statutory regulation or exceeds the permitted use, you will need to obtain permission directly from the copyright holder. 